\title{
Farmer preferred traits and genotype choices in Solanum aethiopicum L., Shum group
}

Brenda Nakyewa', Godfrey Sseremba ${ }^{1 *}$ D, Nahamya Pamela Kabod ${ }^{1}$, Moses Rwothtimutung ${ }^{1}$, Tadeo Kyebalyenda', Kenneth Waholi ${ }^{1}$, Ruth Buteme ${ }^{1}$, Mildred Julian Nakanwangi ${ }^{1}$, Gerard Bishop ${ }^{2^{*}}$ and Elizabeth Balyejusa Kizito ${ }^{1^{*}}$

\begin{abstract}
Background: Solanum aethiopicum L. is a nutrient dense African indigenous vegetable. However, advancement of its improved varieties that can increase productivity, household income, and food security has not been prioritized. Further still, studies on some of the crops that have been worked have indicated that it is not a guarantee that the improved varieties will be accepted by the end users and therefore there is need to identify and profile what genotypes are of interest to farmers and their preferred traits through inclusive participatory evaluations.

Methodology: Farmer participatory evaluations were conducted to profile farmers' traits of interest and preferred genotypes. A total of 24 genotypes were established in three replications in 6 farms in 3 districts; Wakiso, Mukono, and Luwero as these are the major producing districts of the vegetable in Uganda. A total of 177 sex-disaggregated farmers were engaged in scoring the genotypes for pest, disease and drought tolerance, general appeal, leaf yield, leaf texture, and seed yield for best 10 genotypes under each variable.

Results: Non-significant differences in trait $(p>0.05)$ and genotype preferences $(p>0.05)$ were obtained between men and women. The most desired farmer traits were seed and leaf yield, followed by pest and disease resistance. The overall preferred genotype in terms of disease and pest resistance, leaf yield, leaf texture, and seed yield were E12 followed by E11.

Conclusion: Gender does not seem to influence farmer choices for the S. aethiopicum, Shum group, indicating an opportunity for single variety prototype advancement by breeders and dissemination by seed companies.
\end{abstract}

Keywords: African indigenous vegetables, Farmer trait preferences, Variety adoption

\section{Background}

African eggplant (Solanum aethiopicum L.) [1] is classified into four morphological groups based on use namely Gilo, Shum, Kumba, and Aculeatum [2, 3]. Gilo and Shum are cultivated for their fruits and leaves, respectively. Kumba is cultivated for both fruits and leaves

\footnotetext{
* Correspondence: gsseremba16@gmail.com; Gerard.Bishop@niab.com; Ikizito08@gmail.com

'Department of Agricultural and Biological Sciences, Faculty of Science and Technology, Uganda Christian University Mukono, P.O. Box 4, Mukono, Uganda

${ }^{2}$ National Institute of Agricultural Botany, East Malling Research, Kent, UK
}

while Aculeatum is ornamental. The Gilo group is globally cultivated while Shum is most common in Uganda [4], Nigeria, and Cameroon. In Uganda, the Shum group is locally known as 'Nakati' where it earns livelihood to over 4,000,000 people in urban and peri-urban areas. In this study, we focused on the Shum group (leafy type) which is culturally, nutritionally, and economically integrated with several communities in Uganda; and the crop has in previous studies been referred to as African eggplant Shum, Solanum aethiopicum Shum, S. aethiopicum Shum or simply Shum by Sseremba et al. [5-8]

C C The Author(s). 2021 Open Access This article is licensed under a Creative Commons Attribution 4.0 International License, which permits use, sharing, adaptation, distribution and reproduction in any medium or format, as long as you give appropriate credit to the original author(s) and the source, provide a link to the Creative Commons licence, and indicate if changes were made. The images or other third party material in this article are included in the article's Creative Commons licence, unless indicated otherwise in a credit line to the material. If material is not included in the article's Creative Commons licence and your intended use is not permitted by statutory regulation or exceeds the permitted use, you will need to obtain permission directly from the copyright holder. To view a copy of this licence, visit http://creativecommons.org/licenses/by/4.0/. The Creative Commons Public Domain Dedication waiver (http://creativecommons.org/publicdomain/zero/1.0/) applies to the data made available in this article, unless otherwise stated in a credit line to the data. 
who suggested this naming based on works of Adeniji et al. [2,3]. To emphasize, the Shum group being a leafy vegetable, is cultivated for its leaves which are used as a necessary accompaniment to staple foods in Africa contributing a rarely appreciated food and nutrition security especially for vulnerable populations $[9,10]$. S. aethiopicum is much appreciated bitter flavor which is preferred for sauce to go with banana cake (matoke) in Buganda. Culturally, it is associated with widely held beliefs in marriage ceremonies.

S. aethiopicum being an AIV has received less attention in research and productivity is low. Among the causes of low productivity include drought susceptibility $[5,6]$, pests and diseases, limited access and availability of quality seed, and high post-harvest deterioration [11, 12]. Development and advancement of improved varieties can increase productivity, household income, and food security [13]. For example, improved potato varieties in Nepal yielded more than the local varieties (15.4 ton/ha and 13.1 ton//ha) $[14,15]$. However, it is not always obvious that farmers will adopt the improved varieties; therefore, it is important to engage them as end users during the variety development and evaluation process [16].

A number of factors may account for a low adoption of new varieties; this is because the interests of the breeders or researchers may not match famers' preferences since they are always multivariate in nature [17]. For example, when improved potato varieties that are tolerant to diseases and highly yielding were developed in Ethiopia, the adoption rate was only $23 \%$ and this was probably because yield was not the only trait of preference by farmers [18]. While there is ready market for $S$. aethiopicum, farmers may not necessarily or rapidly adopt improved varieties unless fronted genotypes meet market's interests $[14,19]$. Further, the major variety selection criteria for vegetable breeders are pest and disease resistance, yield and taste preference; however, these are non-exhaustive and may not be applicable to understand location specific preferences [20]. This scenario creates a challenge to breeders to always work with the end users right from definition of breeding goals through variety development and testing as well as feedback $[20,21]$.

Participatory variety evaluations (PVE) bring together in a field setting to rank traits of importance such as yield, quality traits, resistance to pest, and disease resistance [20]. PVEs enable breeders have a deeper understanding of traits that are relevant to both the farmers for informing breeding goals [22, 23]. PVEs underpin optimistic changes in farmers' perceptions and willingness to adopt the new varieties as their subjective preferences for instance in relation to gender for the specific characteristics maybe considered during the breeding process [24]. Considering gender in PVE or gender disaggregated participatory plant breeding is also key in order to take care of the varied preferences [25]. For example, when evaluating millet varieties in Botswana, women's traits of interest were yield, early maturity and ease of hand harvesting while men only considered yield and quality of the straw [24]. Kolech et al. [20] also noted that, when evaluating potato varieties in Ethiopia, men participants were more concerned with market related traits while women attached importance to suitability of sequential harvesting. Limited information is available for S. aethiopicum, Shum group on farmer preferred traits and genotypes. This study therefore focused on identifying preferred leaf morphological traits and profiling S. aethiopicum, Shum group genotypes preferred by the farmers. The research questions asked were (i) which S. aethiopicum, Shum group genotypes meet farmer expectations and why? (ii) What are the farmers' S. aethiopicum, Shum group preferred traits and why?

\section{Materials and methods \\ Study area and target population}

The study was conducted in central Uganda in the districts of Wakiso (longitude $00^{\circ} 24^{\prime} \mathrm{N}$, Latitude $32^{\circ} 32^{\prime} \mathrm{E}$ ), Luwero (longitude $00^{\circ} 50^{\prime} \mathrm{N}$, Latitude $32^{\circ} 30^{\prime} \mathrm{E}$ ), and Mukono (longitude $00^{\circ} 20^{\prime} \mathrm{N}$, Latitude $32^{\circ} 45^{\prime} \mathrm{E}$ ). The three districts were selected because they are the leading S. aethiopicum producing areas in Uganda [19]. This area is dominated by the Baganda tribe. All the areas receive bimodal rainfall with rain peaks in months of March and November. The study purposively selected small-scale farmers who typically grow $S$. aethiopicum as a vegetable or seed or both. S. aethiopicum in Uganda is typically grown by small scale farmers whose holdings average 2 acres.

\section{Study design}

A mixed methods approach was used to get genotype preferences from the different African eggplant farmers. Quantitative data was collected by farmers physically evaluating plots with different genotypes. Qualitative data was then collected sex disaggregated focus group discussions to get the elaborations for the farmers' traits of preference [26].

\section{Sampling method and sample size}

Multistage sampling was used in the study. Purposive sampling was used to obtain the leading districts and farmer groups in each district for S. aethiopicum, Shum group vegetable production. Cluster sampling was then applied whereby commercial farmers (both men and women) were separately selected from each farmer group to participate in the study. A total of 177 farmers participated in the evaluation process. Six key 
informants (a man and a woman from each district) who were lead commercial farmers were purposively selected and six sex disaggregated focus group discussions were conducted (two from each location).

\section{Field layout and planting}

Six fields per district with three replications were used to grow 24 different $S$. aethiopicum Shum group genotypes. The study genotypes have previously been described for morphological distinctiveness by Sseremba [12]. Each plot per field had four rows with a spacing of $60 \mathrm{~cm}$ between rows and $30 \mathrm{~cm}$ within rows. Evaluations were made on the two middle rows. Fields in Wakiso and Luwero were planted in August 2019 while that in Mukono was planted in November 2019, due to relative differences in onset of the rains for planting.

\section{Data collection}

\section{Genotype selections}

At vegetative stage of crop growth between the seventh and eighth week after planting, the farmers were engaged in individual selection by ranking their best ten performing genotypes out of 24. Ranking was based on farmer perceptions of damage by pests and disease, leaf yield, general appeal, drought resilience, and seed yield. Field participatory evaluation sessions were guided by researchers and consisted of 10 farmers per group. Each group evaluated all plots, and thereafter they were disaggregated by gender to form new focus group discussions over their selections.

\section{Farmers traits of preference}

Sex disaggregated focus group discussions of not more than 10 participants were conducted ( 2 per location) to get an in-depth understanding of farmer preferences to get farmers traits of interest in S. aethiopicum. Farmers mentioned important traits for fresh leaf produce and for seed. Information on how they decide during selection was also picked. Further, two key informant interviews of lead farmers (a man and a woman) per location were also conducted. A lead farmer in this study was one who had grown the vegetable every year for at least 10 years. Farmers mentioned the key traits they use to identify their ideal Nakati vegetable. They also identified common pests and diseases that attack $S$. aethiopicum and how they were controlling them. The traits were then grouped into vegetable production and market preferences. Vegetable production traits included pest and disease resistance, drought tolerance while market preferences included general appeal, leaf yield, and leaf texture.

\section{Data analysis}

\section{Farmer genotype preferences}

Scores made by the individual farmers on disease resistance, pest resistance, drought tolerance, general appeal, leaf yield, leaf texture, and seed yield were entered in MS-Excel (2016) and exported to GenStat 12th edition for $F$ test on farmer preferences at 5\% significance level. Mean squares of farmer scores were computed to get relationships and interactions between location, gender, and genotype. Cross tabulations were then used to get variety preferences per location and overall preferences. The overall mean of the six attributes was computed and the overall (average) preference score of a given genotype was estimated. The best ten farmers' overall genotype preferences were got by getting the mean of the first and second scores for each parameter and then getting the mean of means. Using the overall mean, then 10 best ranked (scored) genotypes were considered.

\section{Farmers traits of preference}

Qualitative data was recorded verbatim, transcribed, and coded. Themes on traits of preference were used to identify traits preferred by men and those preferred by women. Themes on traits for vegetable production, seed production, market preferences, and common pests and diseases were also made.

\section{Results}

\section{Participant characteristics}

Seventy-nine farmers from Luwero district (39 men and 40 women), 38 from Wakiso (15 men and 23 women), and 60 from Mukono (19 men and 41 women) participated in the study (Fig. 1). Participants mentioned that S. aethiopicum is a nutritious sauce that is prepared even on ceremonial functions. "Although we have other vegetables, $\mathrm{S}$. aethiopicum is the most fronted side sauce on functions such as graduation parties and wedding ceremonies." Male key informant-Mukono.

\section{Farmers' genotype preferences Location, gender, and genotype effects}

There was a very highly significant difference between genotypes $(p<0.01)$ for all parameter preferences, and location by genotype preferences $(p<0.001)$ (Table 1$)$. Choices between men and women, however, were nonsignificant $(p>0.05)$. As detailed in Table 3, E12 emerged the overall most preferred by participants (30 participants) followed by E11 (24 participants), E15 (19 participants), E9 and E18 (14 participants), E1 (13 participants), E4 and E2 (12 participants), E7H and E14GP (11 participants). 


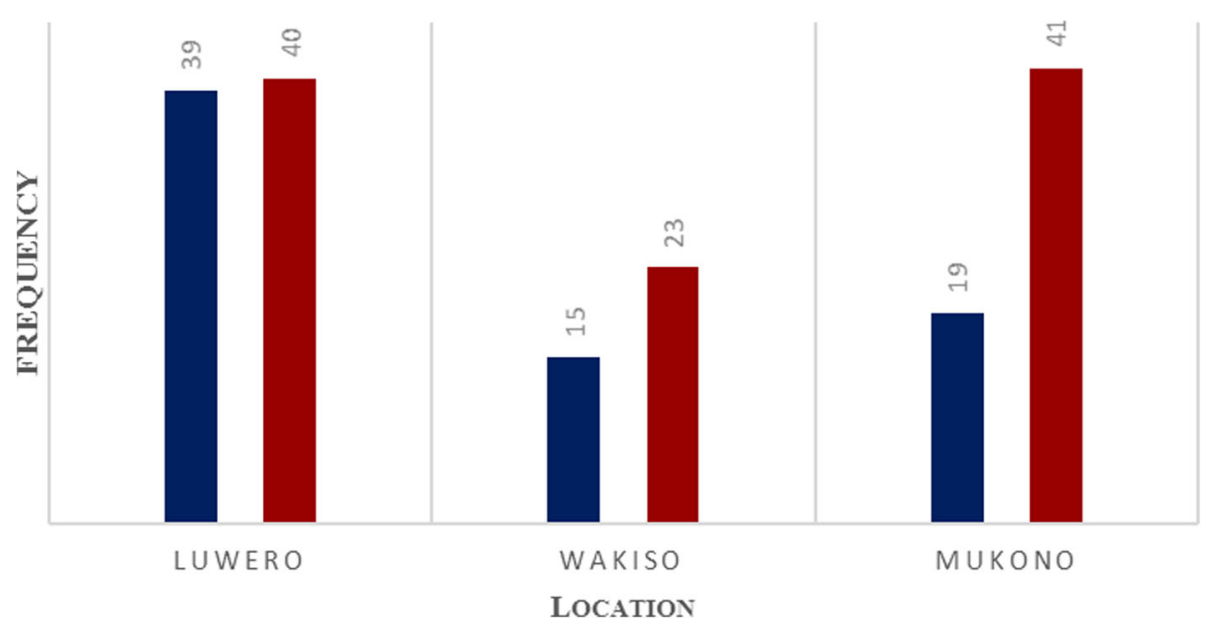

Fig. 1 Number of participants per district

\section{Location specific preferences}

In Luwero District, E12 emerged the most preferred for being disease resistant (Table 2), pest resistant, highest leaf yield, and favorable leaf texture, while E11 was scored as most vigorous and E5 was the highest seed yielding genotype. The overall most highly scored genotype in Luwero District was E12 followed by E11 as shown in Table 2. In Wakiso District, E1 was scored the most disease resistant genotype. E6 was the most pest resistant, E12 was ranked the most vigorous, E12 was the most leaf yielding, favorable leaf texture was E12, and the highest scored genotype for seed yield was E2. The overall most preferred genotype in Wakiso District was E12 followed by E1, E2, and E4. In Mukono District, E12 was the most scored as a disease resistant genotype, E15 was scored the most pest resistant, E11 was the most vigorous, and E12, E11, and E18 were scored the most leaf yielding. For texture preference, E12 was the most scored and E15 was scored the most seed yielding genotype. The overall preferred genotype in Mukono District was E12 followed by 15 and E11.

\section{Genotype selections per trait}

Disease resistance score For disease resistance, participants scored E12 as the most resistant followed by E11, E1, E18, E15 and E9, E4, E14GP, E7H, and E2 as number 10. Under the second-choice score, the best genotypes were E12, E15, E11, E4, E18 and E1, E2, E9, E14GP, and E7H. Getting the mean of the first and second scores, E12 became the most disease resistant followed by E11, E15, E1, E18, E4, E9, E2, E14GP, and E7H took the tenth position (Table 3).

Table 1 Mean squares of farmer scores for the different variables considered among genotypes across test locations

\begin{tabular}{llllllll}
\hline Source of variation & d.f & DRS & PRS & PVS & LYS & LPS & SYS \\
\hline Location (L) & 2 & 2.45 & 1.10 & 2.21 & 0.24 & 1.11 & 0.72 \\
Gender (S) & 1 & 2.08 & 0.19 & 11.44 & 8.90 & 0.16 & $27.99^{* * *}$ \\
Genotype (G) & 23 & $34.97^{* * *}$ & $26.42^{* * *}$ & $62.38^{* * *}$ & $35.50^{* * *}$ & $19.46^{* * *}$ \\
$\mathrm{~L} \times \mathrm{S}$ & 2 & 1.43 & 1.17 & 2.63 & 0.68 & 1.47 & 0.45 \\
$\mathrm{~L} \times \mathrm{G}$ & 46 & $18.48^{* * *}$ & $16.18^{* * *}$ & $17.37^{* * *}$ & $16.55^{* * *}$ & $14.76^{* * *}$ & $22.21^{* * *}$ \\
$\mathrm{~S} \times \mathrm{G}$ & 23 & 9.61 & 8.07 & 9.47 & 6.27 & 10.12 & 4.79 \\
$\mathrm{~L} \times \mathrm{S} \times \mathrm{G}$ & 46 & 7.52 & 8.62 & 6.48 & 8.65 & 8.91 & 5.82 \\
Error & 2702 & 7.84 & 7.76 & 7.70 & 7.86 & 7.92 & 7.95 \\
\hline
\end{tabular}

DRS disease resistance score, PRS pest resistance score, PVS general appeal score, LYS leaf yield score, LPS leaf preference score, SYS seed yield score ***Significance at 0.01 error margin 
Table 2 Farmers' genotype preferences based on selected plant attributes at Luwero, Wakiso, and Luwero districts in Uganda

\begin{tabular}{|c|c|c|c|c|c|c|c|}
\hline Geno name & Disease & Pest & Vigor & LYS & LPS & SYS & Overall \\
\hline \multicolumn{8}{|l|}{ Luwero } \\
\hline E12 & 20 & 14 & 19 & 19 & 13 & 7 & 15 \\
\hline E11 & 14 & 11 & 20 & 17 & 11 & 4 & 13 \\
\hline E15 & 12 & 10 & 12 & 8 & 10 & 5 & 9 \\
\hline E9 & 10 & 7 & 6 & 4 & 10 & 5 & 7 \\
\hline $\mathrm{E} 7 \mathrm{H}$ & 6 & 8 & 10 & 5 & 7 & 4 & 6 \\
\hline E14GP & 8 & 6 & 4 & 7 & 5 & 4 & 5 \\
\hline E3S & 5 & 7 & 9 & 5 & 4 & 4 & 5 \\
\hline E19 & 9 & 6 & 4 & 7 & 5 & 1 & 5 \\
\hline E5 & 1 & 6 & 2 & 4 & 3 & 17 & 5 \\
\hline E18 & 6 & 5 & 7 & 5 & 4 & 3 & 5 \\
\hline \multicolumn{8}{|l|}{ Wakiso } \\
\hline E12 & 4 & 3 & 10 & 8 & 9 & 3 & 6 \\
\hline E1 & 13 & 6 & 2 & 2 & 5 & 4 & 5 \\
\hline E2 & 5 & 5 & 4 & 2 & 4 & 9 & 5 \\
\hline E4 & 7 & 3 & 5 & 4 & 3 & 6 & 5 \\
\hline E11 & 5 & 3 & 9 & 4 & 4 & 2 & 4 \\
\hline E6 & 1 & 7 & 7 & 5 & 3 & 3 & 4 \\
\hline E18 & 8 & 2 & 2 & 4 & 2 & 3 & 3 \\
\hline E20 & 0 & 1 & 6 & 6 & 4 & 3 & 3 \\
\hline E3S & 2 & 1 & 5 & 5 & 4 & 2 & 3 \\
\hline E14GP & 1 & 3 & 5 & 2 & 4 & 3 & 3 \\
\hline \multicolumn{8}{|l|}{ Mukono } \\
\hline E12 & 12 & 9 & 11 & 8 & 11 & 3 & 9 \\
\hline E15 & 6 & 10 & 10 & 6 & 6 & 7 & 7 \\
\hline E11 & 7 & 8 & 13 & 8 & 6 & 2 & 7 \\
\hline E18 & 7 & 8 & 5 & 8 & 4 & 5 & 6 \\
\hline E13 & 8 & 5 & 4 & 7 & 6 & 3 & 5 \\
\hline E14G & 6 & 5 & 5 & 6 & 4 & 6 & 5 \\
\hline E3H & 5 & 7 & 6 & 7 & 4 & 4 & 5 \\
\hline E8 & 6 & 8 & 4 & 5 & 5 & 5 & 5 \\
\hline E9 & 3 & 3 & 5 & 6 & 6 & 7 & 5 \\
\hline E16 & 3 & 6 & 4 & 4 & 7 & 5 & 5 \\
\hline
\end{tabular}

LYS leaf yield score, LPS leaf preference score, SYS seed yield score

Pest resistance score E12 was ranked number 1 by 30 participants as being the most pest tolerant, followed by E15, E11, E7H, E9, E18 and E1, E14GP, and E4 and E2. Under the second choice, E11 and E15 were second best followed by E12, E18, E7H, E14GP, E1, E2, E9, and E4 was the tenth. Considering the mean for the first and second scores, E12 was ranked the most persistent followed by E15, E11, E7H, E18, E9 and E14GP, E1, E2 and $\mathrm{E} 4$ score the tenth position.
General appeal (plant vigor score) Genotypes with the highest scores were E12 (58 participants) followed by E11, E15, E6 and E7H, E9, E4, E19, and E3H and E3S. Under second choice score, the best genotypes were E11, E15, E12, E18, E7H, E14GP, E9, E2, E4, and lastly E1. The mean score of the two scores ranked E11 as the best vigorous followed by E12, E15, E7H, E9 and E18, E4 and E14GP and E1 as the tenth preferred genotype.

Leaf yield score E12 received the highest score as the best choice for the highest leaf yield ( 58 participants) followed by E11, E18, E9, E4, E7H, E14GP (11 participants), E15, E1, and E2. For the second choice, E11 received the highest score (29 participants) followed by E15, E12, E1, E18, E2, E14GP, and E9, E4, E7H. Taking mean scores, E12 emerged most selected (34 participants) followed by E11, E15and E18, E9, E1, E14GP, E4 and $\mathrm{E} 7 \mathrm{H}$, and $\mathrm{E} 2$.

Leaf texture preference scores Genotypes that received the highest number of participants that scored them as best were E12 (35 participants) followed by E11, E9, E15, E14GP, E1, E7H and E4, E18 and E2. Under the secondchoice score, the best scored genotypes were E12 (30 participants), E15, E11 and E9, E4, E18 and E2, E1, E7H) and E14GP. The mean score of the two scores ranked E12 as the most preferred followed by E11, E15, E9, E14GP, E4, E1 (11 participants), E18 and E2, and E7H was scored tenth.

Seed yield scores The E2 genotype received the highest number of participants that scored it as the best seed yielding variety (15 participants). This was followed by E12 and E18, E15 and E1, E4, E7H, E14GP, E9, E11). For genotypes that were ranked as the second-choice score, E2 received the highest number of participants (23 participants), followed by E1, E9 and E4, E14GP and E15, E11 and E12, E7H, and E18. Getting the mean of the first and second scores, E2 received the highest number of participants (19 participants) followed by E2, E4, E9, E15, E12 (13 participants), E14GP, E18, E11, and E7H.

\section{Ranking of important traits by farmers in S. aethiopicum Shum group}

During the focus group discussion, a list of leaf morphological traits was mentioned that included leaf size, number of leaves, general appeal, damage by pest and disease, time. Thirty-five per cent of the farmers preferred a genotype with high seed yield in S. aethiopicum Shum group production (Fig. 2). These found it more profitable to grow for seed rather than for vegetable leaf in the market. "Although the seed market is still low, I prefer a genotype that gives more seed yield because the profit from seed is more than 
Table 3 Overall performance of all evaluated genotypes based on average number of farmers choosing a genotype as their first and second priority in respect to selected plant attributes

\begin{tabular}{|c|c|c|c|c|c|c|c|c|c|c|c|c|c|c|c|c|c|c|c|}
\hline \multirow[t]{2}{*}{ Genotype } & \multicolumn{3}{|c|}{ Disease } & \multicolumn{3}{|c|}{ Pest } & \multicolumn{3}{|c|}{ Vigor } & \multicolumn{3}{|c|}{ Leaf yield } & \multicolumn{3}{|c|}{ Leaf texture } & \multicolumn{3}{|c|}{ Seed yield } & \multirow[t]{2}{*}{ Overall } \\
\hline & 1 & 2 & Mean & 1 & 2 & $\overline{\text { Mean }}$ & 1 & 2 & $\overline{\text { Mean }}$ & 1 & 2 & Mean & 1 & 2 & Mean & 1 & 2 & $\overline{\text { Mean }}$ & \\
\hline$\overline{E 12}$ & 44 & 27 & 36 & 30 & 20 & 25 & 58 & 22 & 40 & 49 & 19 & 34 & 35 & 30 & 33 & 14 & 11 & 13 & 30 \\
\hline E11 & 26 & 24 & 25 & 18 & 25 & 22 & 47 & 35 & 41 & 27 & 29 & 28 & 25 & 16 & 21 & 4 & 11 & 8 & 24 \\
\hline E15 & 20 & 26 & 23 & 20 & 25 & 23 & 19 & 24 & 22 & 10 & 21 & 16 & 17 & 20 & 19 & 12 & 13 & 13 & 19 \\
\hline E9 & 20 & 13 & 17 & 16 & 9 & 13 & 14 & 11 & 13 & 13 & 11 & 12 & 20 & 16 & 18 & 7 & 19 & 13 & 14 \\
\hline E18 & 22 & 17 & 20 & 13 & 14 & 14 & 7 & 19 & 13 & 17 & 15 & 16 & 7 & 12 & 10 & 14 & 6 & 10 & 14 \\
\hline E1 & 24 & 17 & 21 & 13 & 11 & 12 & 7 & 6 & 7 & 7 & 17 & 12 & 12 & 10 & 11 & 12 & 21 & 17 & 13 \\
\hline E4 & 16 & 19 & 18 & 9 & 8 & 9 & 13 & 7 & 10 & 11 & 11 & 11 & 8 & 13 & 11 & 10 & 19 & 15 & 12 \\
\hline E2 & 11 & 16 & 14 & 9 & 10 & 10 & 8 & 10 & 9 & 6 & 14 & 10 & 7 & 12 & 10 & 15 & 23 & 19 & 12 \\
\hline E20 & 5 & 10 & 8 & 6 & 8 & 7 & 8 & 13 & 11 & 15 & 13 & 14 & 15 & 8 & 12 & 12 & 19 & 16 & 11 \\
\hline E3S & 8 & 11 & 10 & 9 & 8 & 9 & 11 & 22 & 17 & 16 & 11 & 14 & 9 & 12 & 11 & 6 & 11 & 9 & 11 \\
\hline E14GP & 13 & 10 & 12 & 11 & 14 & 13 & 8 & 12 & 10 & 11 & 13 & 12 & 13 & 8 & 11 & 8 & 13 & 11 & 11 \\
\hline $\mathrm{E} 7 \mathrm{H}$ & 12 & 7 & 10 & 17 & 14 & 16 & 15 & 15 & 15 & 11 & 11 & 11 & 8 & 9 & 9 & 9 & 7 & 8 & 11 \\
\hline E19 & 8 & 18 & 13 & 10 & 11 & 11 & 12 & 6 & 9 & 13 & 11 & 12 & 8 & 8 & 8 & 16 & 10 & 13 & 11 \\
\hline E5 & 6 & 3 & 5 & 12 & 9 & 11 & 5 & 5 & 5 & 6 & 7 & 7 & 9 & 10 & 10 & 32 & 19 & 26 & 10 \\
\hline E10 & 7 & 10 & 9 & 4 & 12 & 8 & 8 & 8 & 8 & 10 & 9 & 10 & 12 & 8 & 10 & 19 & 14 & 17 & 10 \\
\hline E8 & 11 & 8 & 10 & 14 & 11 & 13 & 5 & 9 & 7 & 11 & 13 & 12 & 7 & 9 & 8 & 13 & 13 & 13 & 10 \\
\hline E13 & 10 & 16 & 13 & 7 & 10 & 9 & 5 & 12 & 9 & 10 & 10 & 10 & 8 & 12 & 10 & 8 & 8 & 8 & 10 \\
\hline E14G & 8 & 5 & 7 & 9 & 7 & 8 & 5 & 10 & 8 & 13 & 11 & 12 & 5 & 9 & 7 & 12 & 11 & 12 & 9 \\
\hline $\mathrm{E} 3 \mathrm{H}$ & 9 & 7 & 8 & 10 & 11 & 11 & 11 & 12 & 12 & 11 & 10 & 11 & 12 & 3 & 8 & 5 & 4 & 5 & 9 \\
\hline E6 & 8 & 7 & 8 & 16 & 11 & 14 & 15 & 11 & 13 & 4 & 13 & 9 & 5 & 5 & 5 & 9 & 4 & 7 & 9 \\
\hline E7S & 5 & 5 & 5 & 7 & 6 & 7 & 3 & 11 & 7 & 7 & 7 & 7 & 8 & 4 & 6 & 18 & 16 & 17 & 8 \\
\hline Local check & 3 & 2 & 3 & 12 & 9 & 11 & 4 & 5 & 5 & 8 & 5 & 7 & 5 & 11 & 8 & 18 & 12 & 15 & 8 \\
\hline E16 & 6 & 7 & 7 & 7 & 14 & 11 & 4 & 6 & 5 & 9 & 8 & 9 & 7 & 11 & 9 & 10 & 7 & 9 & 8 \\
\hline E17GP & 7 & 7 & 7 & 6 & 9 & 8 & 10 & 9 & 10 & 7 & 8 & 8 & 7 & 9 & 8 & 8 & 6 & 7 & 8 \\
\hline
\end{tabular}

the vegetable."-male key informant, Mukono. For this reason, these farmers selected vegetables that were highly branching or that grew tall. The potential for high seed yield perceived as the more the branching, the more fruits borne. "We prefer the branched variety that grows tall because it gives more seed yield"-women FGD Luwero. 23.5\% of the farmers grew the vegetables for leaf production and leaf yield was important. They mentioned that highly branching genotypes and plant height were important traits in selecting such vegetable lines. "We prefer a variety that gives so many branches and grows tall because the more the branches, the more the leaves and the more income."-women FGD, Mukono.

This was followed by pest resistance $(11.8 \%)$. "When pests attack the plant, they eat leaves and stalks and they do not grow again reducing leaf and seed yield."-female key informant, Mukono. Furthermore, "Management of the pests is expensive and therefore we get low profits."-men FGD, Wakiso. Farmers also mentioned that seed which is infested does not germinate. "Seed that affected by fruit rot does not germinate and once a buyer takes, they will never buy from you again."-female FGD, Wakiso. Furthermore, infested vegetables are also not bought on the market. Common pests mentioned by participants included maggots, grasshoppers, lady bird beetle, cut worm, aphids, monkeys, spider web, caterpillar, and mites.

Participants (7.8\%) also liked disease resistant genotypes since diseases affect the quantity and quality of the yield. Common diseases mentioned by farmers that attacked S. aethiopicum included fruit rot, wilt, and leaf spot. Participants (7.8\%) liked S. aethiopicum Shum with a good taste (the one that is not bitter).

Early maturity was also a trait mentioned by participants (5.9\%). They preferred a variety that takes a shorter time to mature (6 weeks for the vegetable and 12 weeks for seed). Farmers (3.9\%) also liked a genotype that takes a short time (3 to $4 \mathrm{~min}$ ) to get ready when cooked. 


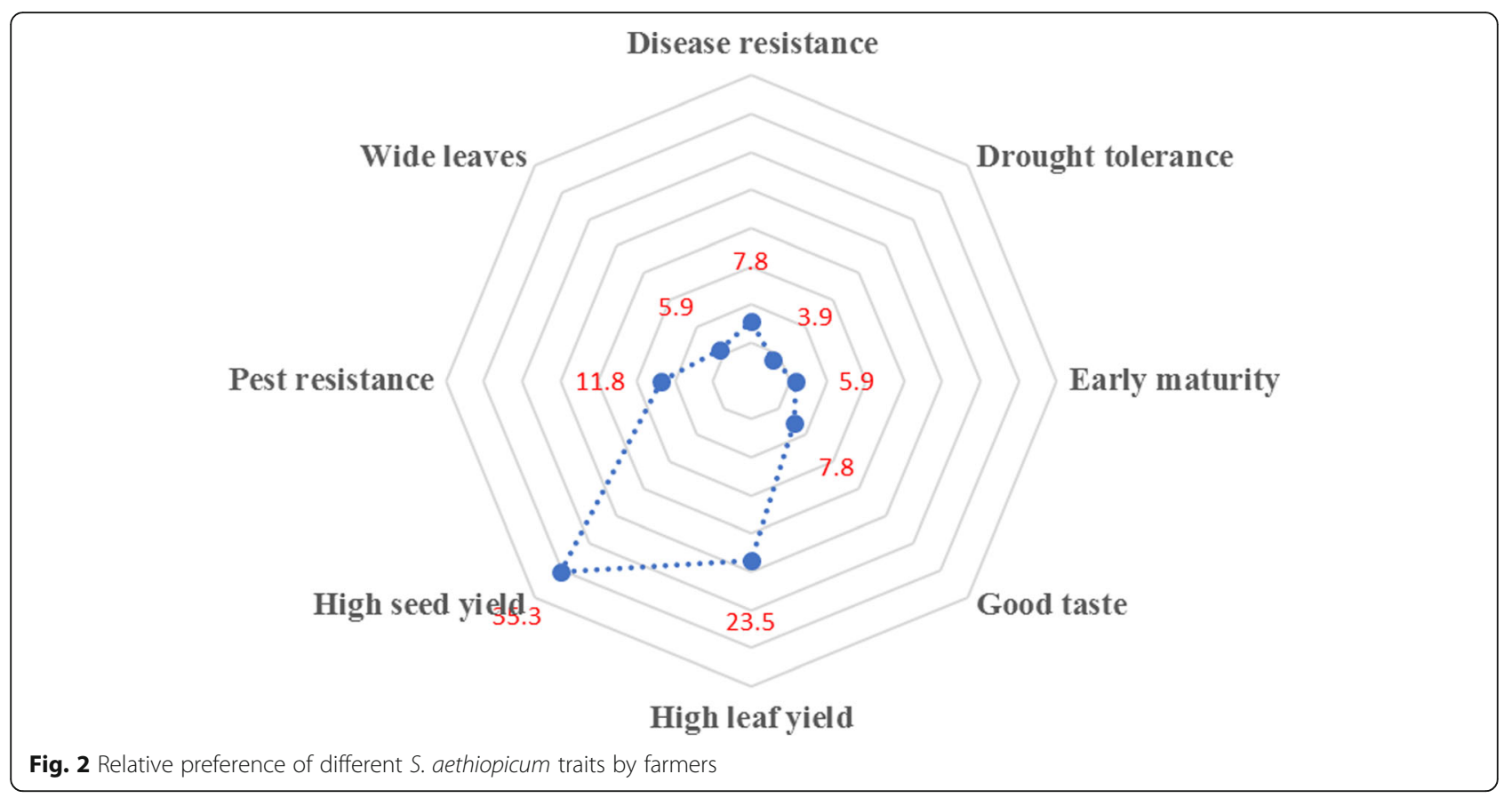

Figure 2 also indicates that drought tolerance was among the traits which farmers wished to have (3.9\%). "One of the major constraints to S. aethiopicum production is drought and this has greatly affected yield because the general appeal is poor."-men FGD, Mukono. To women, irrigation was a burden, "the water sources are far and so irrigation is a very big challenge to us and therefore we shall be glad to get a genotype that is drought resistant."-women FGD, Wakiso.

\section{Discussion}

\section{Farmers genotypes of preference}

E12 had the highest score for diseases and pest tolerance, vigor, leaf yield, and leaf texture. This genotype showed no sign of disease and pest infestation in all farmer fields. Whereas E12 had the best rank, an earlier sensory taste by consumers gave a feedback that the genotype is bitter (unpublished data). It is perceived to be culturally degrading to beneficiaries and unethical issue by researchers to advance a non-palatable, poor taste, or low-quality food item in society. This consequently leaves us with options to forward E11 and E15 as the farmers' choices. The criteria on taste- and visual-based choice presents a disconnect between consumer and farmer goals. During key informant interviews, other traits such as cooking time and time to maturity emerged to be of interest by the farmers. Common diseases mentioned by farmers that attacked $S$. aethiopicum were not differing from findings by Dinssa et al. [25] on common pests for S. aethiopicum. Participants mentioned that pests affect the yield and quality of both the vegetable and seed.

\section{Farmer preferred traits}

Seed yield came out as the most important trait as it was mentioned by majority of the participants. Participants mentioned that they preferred a genotype that gave high seed yield because growing for seed was more profitable than the vegetable. Preference for seed yield created another need for seed market linkages. Farmers also preferred genotypes that gave many branches and grew tall since many branches yield more fruits and hence much seed. This is corroborated by findings of Jameson and Song [27] who reported that branching had a positive correlation with seed yield. Abady et al. [28] and Banla et al. [29] studies on farmer ground nut trait preferences in Ethiopia and Togo, respectively, also indicated a positive correlation of branching with seed yield.

Farmers also preferred a genotype that yields many and wide leaves as this would be the best for commercial vegetable production. This relates to Adeniji and Aloyce [30] and Diallo et al. [31] findings on farmer preferences for Ethiopian mustard and sorghum in Ethiopia and Mali, respectively. The vegetable market also prefers wide leaves [19] and therefore farmers prefer a variety that will have a ready market.

The disease and pest resistance traits were liked because pests affect the quality of the vegetable leaves, hence attracting low prices. Farmers also incur a lot of expenses managing the pests and diseases cumulating on the cost of production. This trait is similar to the characteristics preferred by Sorghum farmers in Zimbabwe [32]. 
Farmers' preference for drought tolerant genotypes was because drought lessens the vigor of the plant affecting its yield $[4,5]$. This is in agreement with farmer traits of preference for rice varieties in Kenya [33]. The finding also relates to farmer preferences for ground nut and cowpea varieties in Togo and Namibia [29, 34]. To women, drought is a major challenge because they find it hard to fetch water for irrigation since most of the fields are not near sources of water.

Taste was also a desired trait because the market prefers mild bitter taste (tasty or good taste) genotypes and imperatively farmers like the trait since they produce for the market. Farmers are also the first market for the vegetables and therefore preferred a genotype with a good taste [35]. In addition to that, a soft genotype was preferred by farmers because it takes a short time to cook.

\section{Conclusion}

There were no differences in traits and genotypes of $S$. aethiopicum, Shum group preferred by men and women. The most considered farmer traits are seed and leaf yield, followed by pest and diseases resistance. The overall preferred genotype in terms of disease and pest resistance, leaf yield, leaf texture, and seed yield were E12 followed by E11. Whereas E12 emerged the best overall based on visual scores, its taste may not be liked by consumers. Aside from E12, the most preferred genotype was the green genotype (E11) for market and the purple genotype (E15) for personal consumption. This shows a mismatch between consumer and farmer preferences hence a need for a keener understanding of perceptions across the value chain. Thus, sensory evaluations should always accompany visual observations because genotypes excelling for physical/visual attributes may not meet the sensory preferences.

\section{Supplementary Information}

The online version contains supplementary material available at https://doi. org/10.1186/s13002-021-00455-y.

Additional file 1. Initial conditional approval.

Additional file 2. Final approval.

Additional file 3. Copy of farmers consent form.

Additional file 4. Study tools.

\section{Acknowledgements}

We are grateful to farmers who participated in the evaluations for their time, knowledge and information. Special thanks also go the Ms. Aisha Atine for her support in the set up and maintenance of the field trials and during the data collection process. The mixed methods strategy opted was based on skills gained during a short course on 'Gender-Responsive Responsive Researchers Equipped for Agricultural Transformation (GREAT)' organized by Makerere University and Cornell University with funding from Bill and Melinda Gates Foundation. This study was funded by the Biotechnology and Biological Sciences Research Council (BBSRC) GCRF SASSA initiative grant number BB/R020655/1.

\section{Authors' contributions}

BN participated in designing the data collection tools, collecting data, analysis and drafting of the manuscript. GS contributed in setting up the trials, designing the data collection tools, analysis, and writing the manuscript. NPK set out the field trials, participated in the data collection process and drafting the manuscript. MR, TK, and KW were involved in setting out trials, supervised their management, collected and did data entry. RB participated in setting up the trials and drafting of the manuscript. MJN did the general administration and supervision of the study and also contributed in drafting the manuscript. GB and EBK conceived the study, participated in its designed and coordination, and helped to design the manuscript. All authors read and approved the final manuscript.

\section{Funding}

The study was funded by BBSRC GCRF SASSA initiative, grant no. BB/ R020655/1.

\section{Availability of data and materials}

The data can be availed on request.

\section{Declarations}

\section{Ethics approval and consent to participate}

The study protocols were approved by Uganda Christian University Research Ethical Committee (UCU REC) chaired by Professor Peter Waiswa. Further, consent was sought from farmers who volunteered their information. The initial condition approval (S1) and final approval (S2) letters from UCUREC, as well as copy of farmer's consent form (S3) and study tools (S4) are included as supplementary files.

\section{Consent for publication}

Not applicable since the study only involved adults and no other person's data was used.

\section{Competing interests}

The authors declare that they have no competing interests.

Received: 29 August 2020 Accepted: 25 March 2021

Published online: 13 April 2021

\section{References}

1. Lester RN. Taxonomy of scarlet eggplants, Solanum aethiopicum L. Acta Hortic. 1986;182:125-32.

2. Adeniji OT, Kusolwa PM, Reuben SO. Genetic diversity among accessions of Solanum aethiopicum L. groups based on morpho-agronomic traits. Plant Genet Res. 2012;10(3):177.

3. Adeniij OT, Kusolwa P, Reuben SW. Morphological descriptors and micro satellite diversity among scarlet eggplant groups. Afr Crop Sci J. 2013;21(1): 37-49.

4. Sseremba G, Kabod NP, Katwijukye Kasharu A, Nkalubo Jaggwe J, Masanza M, Balyejusa KE. Diversity and distribution of African indigenous vegetable species in Uganda. Int J Biodivers Conserv. 2017;9(11):334-41.

5. Sseremba G, Tongoona P, Eleblu JS, Danquah EY, Kaweesi T, Baguma Y, et al. Stability of Solanum aethiopicum Shum accessions under varied water deficit stress levels and identification of pertinent breeding traits for resistance to water shortage. Euphytica. 2018;214(1):1-11.

6. Sseremba G, Tongoona P, Eleblu J, Danquah EY, Kizito EB. Heritability of drought resistance in Solanum aethiopicum Shum group and combining ability of genotypes for drought tolerance and recovery. Sci Hortic. 2018; 240:213-20. https://doi.org/10.1016/j.scienta.2018.06.028.

7. Sseremba G, Tongoona P, Eleblu JS, Danquah EY, Kizito EB. Linear discriminant analysis of structure within African eggplant 'Shum'. Afr Crop Sci J. 2018;26(1):37-48. https://doi.org/10.4314/acsj.v26i1.3.

8. Sseremba G, Tongoona P, Yaw Eleblu JS, Yirenkyi Danquah E, Kabod NP, Balyejusa KE. Morphological distinctiveness between Solanum aethiopicum Shum group and its progenitor. J Plant Breed Crop Sci. 2017;9(8):118-29.

9. Apolot MG, Acham H, Ssozi J, Namutebi A, Masanza M, Jagwe J, et al. Postharvest practices along supply chains of Solanum aethiopicum (shum) and Amaranthus lividus (linn) leafy vegetables in Wakiso and Kampala Districts, Uganda. Afr J Food Agric Nutr Dev. 2020;20(3):15978-91. 
10. Dweba TP, Mearns MA. Conserving indigenous knowledge as the key to the current and future use of traditional vegetables. Int J Inf Manag. 2011;31(6): 564-71. https://doi.org/10.1016/j.jijinfomgt.2011.02.009.

11. Ojiewo C, Tenkouano A, Hughes JD, Keatinge JD. Diversifying diets: using indigenous vegetables to improve profitability, nutrition and health in Africa. Diversifying food and diets: Using agricultural biodiversity to improve nutrition and health. Earthscan. 2013;1:291-302.

12. Sseremba G. Genetic Diversity and breeding of Solanum aethiopicum Shum group for drought tolerance. (Doctoral dissertation, University of Ghana). 2019.

13. Cernansky R. Super vegetables: long overlooked in parts of Africa, indigenous greens are now capturing attention for their nutritional and environmental benefits. Nature. 2015:522(7555):149-52.

14. Diouf M, Gueye M, Samb PI. Participatory varietal selection and agronomic evaluation of African eggplant and roselle varieties in Mali. Eur Sci J. 2017; 13(30):327-40. https://doi.org/10.19044/esj.2017.v13n30p327.

15. Kafle B, Shah P. Adoption of improved potato varieties in Nepal: a case of Bara District. J Agric Sci. 2012;7(1):14-22.

16. Danial D, Parlevliet J, Almekinders C, Thiele G. Farmers' participation and breeding for durable disease resistance in the Andean region. Euphytica. 2007;153(3):385-96. https://doi.org/10.1007/s10681-006-9165-9.

17. Vom Brocke K, Trouche G, Weltzien E, Barro-Kondombo CP, Gozé E, Chantereau J. Participatory variety development for sorghum in Burkina Faso: Farmers' selection and farmers' criteria. Field Crop Res. 2010;119(1): 183-94. https://doi.org/10.1016/j.fcr.2010.07.005.

18. Kolech SA, Halseth D, De Jong W, Perry K, Wolfe D, Tiruneh FM, et al. Potato variety diversity, determinants and implications for potato breeding strategy in Ethiopia. Am J Potato Res. 2015;92(5):551-66. https://doi.org/10.1007/ s12230-015-9467-3.

19. Kasharu AK, Kizito EB, Masanza M, Namutebi JJ. Quantifying physical and economic losses of African indigenous vegetable Solanum aethiopicum along the commercial supply value chain. J Econ Sustain Dev. 2019;10(2):67-77.

20. Kolech SA, De Jong W, Perry K, Halseth D, Mengistu F. Participatory variety selection: a tool to understand farmers' potato variety selection criteria. Open Agric. 2017;2(1):453-63.

21. Van Etten J, Beza E, Calderer L, Van Duijvendijk K, Fadda C, Fantahun B, et al. First experiences with a novel farmer citizen science approach: crowdsourcing participatory variety selection through on-farm triadic comparisons of technologies (tricot). Exp Agric. 2019;55(S1):275-96. https:// doi.org/10.1017/S0014479716000739.

22. Soleri D, Cleveland DA. Farmers' genetic perceptions regarding their crop populations: An example with maize in the Central Valleys of Oaxaca, Mexico. Econ Bot. 2001;55(1):106-28. https://doi.org/10.1007/BF02864550.

23. Teeken B, Olaosebikan O, Haleegoah J, Oladejo E, Madu T, Bello A, et al. Cassava trait preferences of men and women farmers in Nigeria: implications for breeding. Econ Bot. 2018;72(3):263-77. https://doi.org/10.1 007/s12231-018-9421-7.

24. Christinck A, Weltzien E, Rattunde F, Ashby J. Gender differentiation of farmer preferences for varietal traits in crop improvement: evidence and issues: CGIAR System Management Office and International Center for Tropical Agriculture (CIAT); 2017.

25. Dinssa FF, Hanson P, Dubois T, Tenkouano A, Stoilova T, Hughes JD, et al. AVRDC - The World Vegetable Center's women-oriented improvement and development strategy for traditional African vegetables in sub-Saharan Africa. Eur J Hortic Sci. 2016;81(2):91-105. https://doi.org/10.17660/eJHS.201 6/81.2.3.

26. Mudege NN, Mdege N, Abidin PE, Bhatasara S. The role of gender norms in access to agricultural training in Chikwawa and Phalombe, Malawi. Gend Place Cult. 2017;24(12):1689-710. https://doi.org/10.1080/0966369X.2017.13 83363.

27. Jameson PE, Song J. Cytokinin: a key driver of seed yield. J Exp Bot. 2016; 67(3):593-606. https://doi.org/10.1093/jxb/erv461.

28. Abady S, Shimelis H, Janila P. Farmers' perceived constraints to groundnut production, their variety choice and preferred traits in eastern Ethiopia: implications for drought-tolerance breeding. J Crop Improv. 2019;33(4):50521. https://doi.org/10.1080/15427528.2019.1625836.

29. Banla EM, Dzidzienyo DK, Beatrice IE, Offei SK, Tongoona P, Desmae H. Groundnut production constraints and farmers' trait preferences: a prebreeding study in Togo. J Ethnobiol Ethnomed. 2018;14(1):1-4.

30. Adeniji OT, Aloyce A. Participatory identification of agronomic and leaf quality traits in Ethiopian mustard (Brassica carinata A. Braun) genotypes in Tanzania. Agric Biol J N Am. 2014;5(6):245-51.
31. Diallo C, Isaacs K, Gracen V, Touré A, Weltzien Rattunde E, Danquah EY, et al. Learning from farmers to improve sorghum breeding objectives and adoption in Mali. J Crop Improv. 2018;32(6):829-46. https://doi.org/10.1 080/15427528.2018.1531800.

32. Mativavarira M, Mwenje E, Van Rooyen A, Jumbo BM, Sisito G, Dimes J. Onfarm Evaluation of sweet sorghum cultivars in Zimbabwe using participatory approaches to understand farmers' trait preferences and cropping systems. Unpublished.

33. Musila RN, Sibiya J, Derera J, Kimani JM, Tongoona P, Danda K. Farmers' perceptions of, and preferred traits in, rice varieties in the Coastal Region of Kenya and their implications for breeding. J Int Cooper Agric Dev. 2018;16: 20-30.

34. Horn L, Shimelis H, Laing M. Participatory appraisal of production constraints, preferred traits and farming system of cowpea in the northern Namibia: implications for breeding. Legum Res. 2015;38(5):691-700.

35. Kamga RT, Kouamé C, Atangana AR, Chagomoka T, Ndango R. Nutritional evaluation of five African indigenous vegetables. J Hortic Res. 2013;21(1):99-106.

\section{Publisher's Note}

Springer Nature remains neutral with regard to jurisdictional claims in published maps and institutional affiliations.
Ready to submit your research? Choose BMC and benefit from:

- fast, convenient online submission

- thorough peer review by experienced researchers in your field

- rapid publication on acceptance

- support for research data, including large and complex data types

- gold Open Access which fosters wider collaboration and increased citations

- maximum visibility for your research: over $100 \mathrm{M}$ website views per year

At BMC, research is always in progress.

Learn more biomedcentral.com/submissions 